\title{
Interpolative Empirical Model for Stability of Sway Frames
}

\author{
Solomon Teminusi Orumu Ph.D \\ Department of Civil Engineering and Hydrology Niger Delta University Wilberforce Island, Nigeria \\ The research was sponsored by ABSOVI@COY NIG.
}

\begin{abstract}
This paper derives mathematical formulae for the estimation of critical loads for rigid sway frames with pinned or fixed base restraints. This is informed by understanding that the critical loads of sway frames have values, which always fall within those of a pinned ended strut and a cantilever strut zero depending on the beam to column stiffness. Based on this, interpolation formulae that rely on the stiffness of the sway frame are developed using numerical integration. The results of the method have been found to be striking the result of the exact method. The method can be extended to multi-bay, multi-storey sway frames with ease.
\end{abstract}

Keywords: - Sway frame, critical load, stability functions, and Euler load.

\section{INTRODUCTION}

The critical load is apparently the most important parameter for judging the stability of structures, at least for now. Its determination, for that matter, occupies the center stage in the stability analysis of structures. The exact solution through full bucking analysis evolved from the development of stability functions to other concepts such as substitute frame ${ }^{1}$, the modified Grinter frame ${ }^{2}$, the equivalent column approach and the stiffness distribution technique among others, proposed at various stages by respective authors. However, the determination of effective length factor for whole composite frames, based on these methods is involving both in analytical and occupational complexity as well as cost. Therefore, engineers have long recognized the need to develop simple hand methods, which could be used for quick evaluation of the buckling load of columns and building frames. Approximate methods have been developed in the works of Horne ${ }^{3}$, Bolton ${ }^{4}$, Leipholz ${ }^{5}$ and Anderson ${ }^{6}$ where the critical load ratio was determined as a function of the maximum sway of the frame due to an assumed mechanism. Orumu ${ }^{7}$ Hoenderkamp ${ }^{8}$ and Orumu ${ }^{9}$ have also developed hand methods of solution for stability problems.

\section{THE PROPOSED METHOD}

Sway frames are assumed to fail when the columns fail. The attached beams can be viewed to act as partial elastic restraints to the columns while the foundation or base supports are assumed to be either fixed or pinned. A relationship between the stiffness of the beam and the level of restraint it gives to the columns in the frame is developed, which enables the critical load of the frame to be determined. From the critical load, the effective length of the entire framework can be found. The approach is essentially different from the recommended approach of the various codes of practice, which proceeds from the determination of the effective lengths of framework to the calculation of critical load, using the effective length determined.

\section{THEORETICAL FORMULATION}

The theoretical framework of the proposed method can be summarized in the following steps:

i. The values of the joint moments and shears are determined as a function of the beam to columns stiffness ratio $\mathrm{K}_{\mathrm{b}} / \mathrm{K}_{\mathrm{c}}$ and the assumed freedoms of a given framework.

ii. The critical stability conditions are invoked for which the flexural and shear stiffness of the frame must tend to zero as instability approaches.

iii. The value of column stiffness modifies or s' obtained is used in the stability function tables to determine the corresponding value of the critical load factor $\lambda_{\mathrm{cr}}=\mathrm{P}_{\mathrm{cr}} / \mathrm{P}_{\mathrm{E}}$ where $\mathrm{P}_{\mathrm{E}}$ is the Euler load.

iv. The values of $P_{c r}$ are plotted against stiffness ratio $K_{b} / K_{c}$, numerical integration of values of the graph is used to derive a simple linear interpolative empirical expression for $\mathrm{P}_{\mathrm{cr}}$.

\subsection{Critical Stability Conditions for Sway Frames}

The critical conditions of zero frame stiffness are derived for two cases of frame with rigidly fixed supports and pinned supports. 


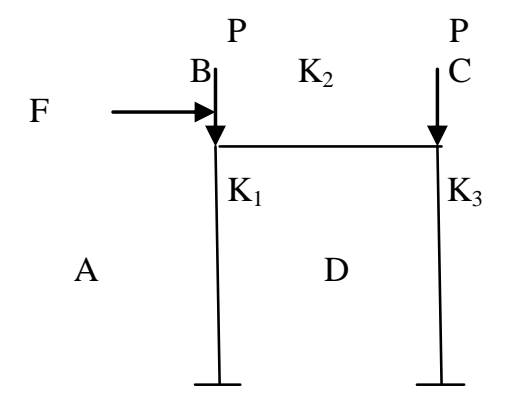

Fig. 1(a) Frame with fixed/pinned feet

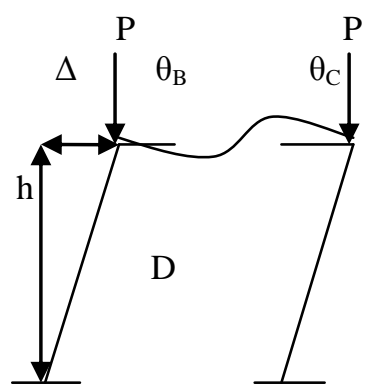

Fig. 1(b) Frame with fixed / pinned feet with sway

\subsection{Frame with fixed supports at base}

Consider the rigid frame shown in Fig. i.a. The freedoms include the rotations and translations at joints $\mathrm{B}$ and $\mathrm{C}$ $\left(\theta_{\mathrm{B}}, \theta_{\mathrm{n}} \Delta\right)$. The moments and shears were determined by Horne and Merchant ${ }^{2}$

$$
\begin{array}{ll}
\mathrm{M}_{\mathrm{B}}=\left(\mathrm{sK}_{1}+4 \mathrm{~K}_{2}\right) \theta_{\mathrm{B}}+2 \mathrm{~K}_{2} \theta_{\mathrm{C}}-\mathrm{s}(1+\mathrm{c}) \mathrm{K}_{1} \Delta / \mathrm{h} & 1 \\
\mathrm{M}_{\mathrm{C}}=2 \mathrm{~K}_{1} \theta_{\mathrm{B}}+\left(\mathrm{s} \mathrm{K}_{1}+4 \mathrm{~K}_{2}\right) \theta_{\mathrm{C}}-\mathrm{s}(1+\mathrm{c}) \mathrm{K}_{1} \Delta / \mathrm{h} & 2 \\
\mathrm{FL}=-\mathrm{s}(1+\mathrm{c}) \mathrm{K}_{1} \theta_{\mathrm{B}}-\mathrm{s}(1+\mathrm{c}) \mathrm{K}_{3} \theta_{\mathrm{C}}+\frac{-2 \mathrm{~s}(1+\mathrm{c})}{\mathrm{m}}\left(\mathrm{K}_{1}+\mathrm{K}_{3}\right) \Delta / \mathrm{h} & 3
\end{array}
$$

Where s, c, s', $\mathrm{n}$ and $\mathrm{m}$ are stability functions.

If frame is symmetric $\left(\left(\mathrm{K}_{1}=\mathrm{K}_{3}\right)\right.$; then $\theta_{\mathrm{B}}=\theta_{\mathrm{C}}$

For critical sway condition, moment and shear stiffness must vanish:

$\mathrm{M}_{\mathrm{B}}=\mathrm{M}_{\mathrm{C}} 0$ and $\mathrm{Fh}=0$

According to Home and Merchant ${ }^{2}$, the following cases of critical load are possible.

$$
\begin{array}{ll}
\text { 1. } & \theta_{\mathrm{B}}=\theta_{\mathrm{C}} \text { and } \Delta=0 \\
\text { 2. } & \theta_{\mathrm{B}}=\theta_{\mathrm{C}} \text { and } \Delta / \mathrm{h}=\mathrm{m} \theta_{\mathrm{B}} / 2 \\
\text { 3. } & \theta_{\mathrm{B}}=\theta_{\mathrm{C}}=\frac{\mathrm{s}(1+\mathrm{c})}{6 \mathrm{CK}_{2} \mathrm{~h}^{\mathrm{h} / \mathrm{R}_{1}}}
\end{array}
$$

However, the authors ${ }^{2}$ showed that case 2 represents the most critical of the three. Back substituting the conditions in case 2 , taking

$\mathrm{n}=\mathrm{sK}_{1} \theta_{\mathrm{B}}[1-\mathrm{m}(1+\mathrm{c}) / 2]$

then

$\mathrm{n}=-6 \mathrm{~K}_{2} / \mathrm{K}_{1}$

For critical stability condition, the frame stiffness will be equal to zero, therefore

$n=-6 K_{b} / K_{c}=-6 K$

\subsection{Frame with Pinned Support at Base}

Consider Fig. 1(b) as a sketch of sway frame pinned at its base. The freedoms are the rotations at B and C $\left(\theta_{\mathrm{B}^{v}} \theta_{\mathrm{C}}\right)$ and sideways $\Delta$ due to rotation at the hinges at $\mathrm{A}$ and $\mathrm{D}$. The moments and shears were determined by Horne and Merchant ${ }^{3}$ as

$$
\begin{array}{ll}
\mathrm{M}_{\mathrm{B}}=\left(\mathrm{s}^{\prime} \mathrm{K}_{1}+4 \mathrm{~K}_{2}\right) \theta_{\mathrm{B}}+2 \mathrm{~K}_{2} \theta_{\mathrm{C}}-\mathrm{s}^{\prime} \mathrm{K}_{1} \Delta / \mathrm{h} & 4 \\
\mathrm{M}_{\mathrm{C}}=2 \mathrm{~K}_{2} \theta_{\mathrm{C}}+\left(\mathrm{s}^{\prime} \mathrm{K}_{1}+4 \mathrm{~K}_{2}\right)-\mathrm{s}^{\prime} \mathrm{K}_{1} \Delta / \mathrm{h} & 5 \\
\mathrm{FL}=\mathrm{s}^{\prime} \mathrm{K}_{1} \theta_{\mathrm{B}}-\mathrm{s}^{\prime} \mathrm{K}_{1} \theta_{\mathrm{C}}+\left(\mathrm{s}^{\prime} \lambda \pi^{2}\right)\left(\mathrm{K}_{1}+\mathrm{K}_{3}\right) \Delta / \mathrm{h} & 6
\end{array}
$$

If frame is symmetric $\left(\mathrm{K}_{1}=\mathrm{K}_{3}\right)$; then $\theta_{\mathrm{B}}=\theta_{\mathrm{C}}$

For critical sway condition, moment and shear stiffness must vanish: thus,

$\mathrm{M}_{\mathrm{B}}=\mathrm{M}_{\mathrm{C}}=0$ and $\mathrm{FL}=0$

Therefore

$\mathrm{s}^{\prime}=6 \lambda \pi^{2} \mathrm{~K}_{2} /\left(6 \mathrm{~K}_{2}-\lambda \pi^{2} \mathrm{~K}_{1}\right)$

\subsection{Empirical modeling}

The next step is to determine the critical load ratio $\lambda$ directly from the stability function tables using beam column stiffness ratio $K_{b} / K_{c}$ in the range $(0, \infty)$ for both fixed and pinned sway frames.

\subsection{Frame with fixed supports}

The stability condition for frame fixed at base is expressed by equation 2 . The critical load ratio determined from stability functions tables are shown in table 2 and plotted as Fig. 3. 
Table 1: Critical Load Ratios for Sway Frame Fixed at Base

\begin{tabular}{|l|ll|l|}
\hline \multicolumn{1}{|c|}{$\mathrm{K}_{\mathrm{b}} / \mathrm{K}_{\mathrm{c}}$} & $\mathrm{n}$ & $($ Eqtn 2$)$ & $\lambda=\mathrm{P}_{\mathrm{cr}} / \mathrm{P}_{\mathrm{E}}$ \\
\hline 0 & 0 & & 0.25 \\
$\left(\mathrm{~K}_{\mathrm{c}}>>\mathrm{K}_{\mathrm{b}}\right)$ & & & \\
1.0 & -6 & & $0.75(0.76)$ \\
$\left(\mathrm{K}_{\mathrm{c}}=\mathrm{K}_{\mathrm{b}}\right)$ & & & \\
10 & -60 & 0.97 \\
$\left(\mathrm{~K}_{\mathrm{c}}=0.1 \mathrm{~K}_{\mathrm{b}}\right)$ & & & \\
$\infty$ & & 1.0 \\
$\left(\mathrm{~K}_{\mathrm{c}}<<\mathrm{K}_{\mathrm{b}}\right)$ & & \\
\hline
\end{tabular}

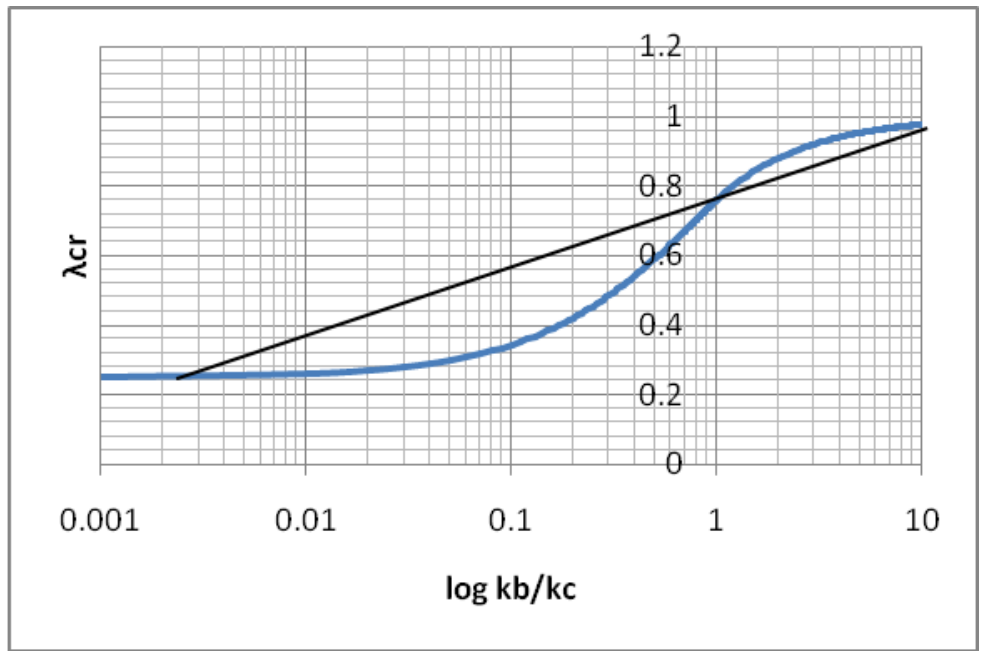

Fig. 2 Plot of $\mathrm{P}_{\mathrm{cr}} / \mathrm{P}_{\mathrm{E}}$ against $\log \mathrm{K}_{\mathrm{b}} / \mathrm{K}_{\mathrm{c}}$ for frame with fixed base support the two segments are clearly visible

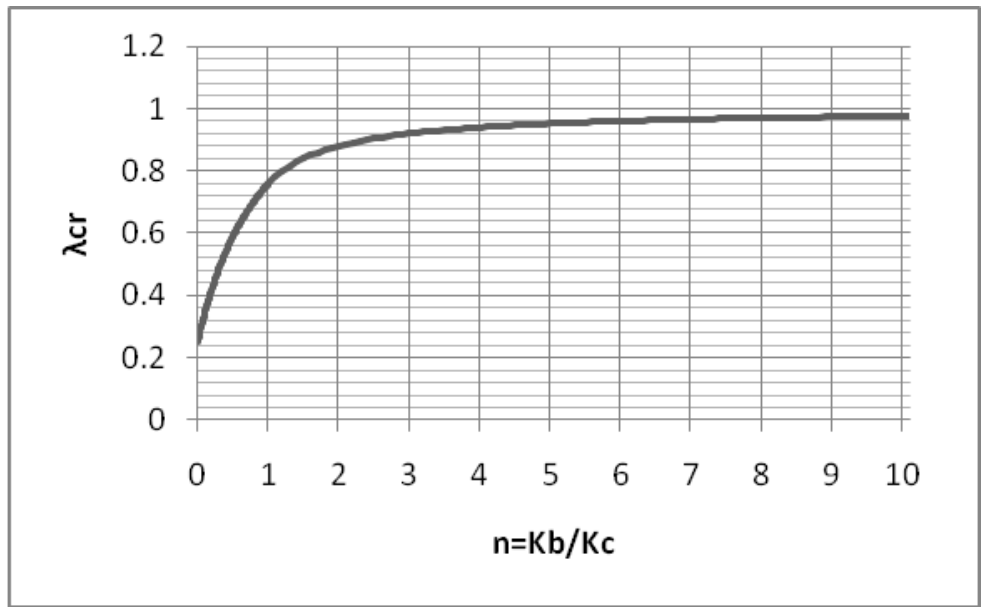

Fig. 3 Plot of $\mathrm{P}_{\mathrm{cr}} / \mathrm{P}_{\mathrm{E}}$ against $\mathrm{K}_{\mathrm{b}} / \mathrm{K}_{\mathrm{c}}$ for frame with fixed base support. Here the two segments are not visible

The $\mathrm{P}_{\mathrm{cr}}$ curve has two distinct segments for $0.76 \leq \lambda \leq 1$ and $0.25 \leq \lambda \leq 0.76$. Using simple numerical integration, the following expressions are derived for the segments $0 \leq \mathrm{K}_{\mathrm{b}} / \mathrm{K}_{\mathrm{c}} \leq 1$ and $1 \leq \mathrm{K}_{\mathrm{b}} / \mathrm{K}_{\mathrm{c}}<\infty$ in Orumu For $\mathrm{K}_{\mathrm{b}} / \mathrm{K}_{\mathrm{c}}>1$

$\mathrm{P}_{\mathrm{cr}}=\mathrm{P}_{\mathrm{E}}\left(1-0.24 \mathrm{~K}_{\mathrm{c}} / \mathrm{K}_{\mathrm{b}}\right)$

8

And for $\mathrm{K}_{\mathrm{b}} / \mathrm{K}_{\mathrm{c}}<1$

$\mathrm{P}_{\mathrm{cr}}=\mathrm{P}_{\mathrm{E}}\left[0.25+1.02 /\left(1+\mathrm{K}_{\mathrm{c}} / \mathrm{K}_{\mathrm{b}}\right]\right)$

Equations 7 and 8 are direct empirical formulae for the determination of critical buckling load of rigid sway frames with fixed bases.

Frame with pinned support

The stability condition for sway frame pinned at base is given equations 6 and 7. Here the solution is iterative using the stability functions. A value of $\lambda$ is guessed and s' calculated from equations 6 and 7 . The critical load Pcr is one that gives the calculated s' same as the value read from the stability function table. The critical load ratio determined from stability functions tables are shown in table 4 and plotted as Fig. 3 
Table 2: Critical Load Ratio for Sway Frame pinned at Base.

\begin{tabular}{|l|l|l|}
\hline \multicolumn{1}{|c|}{$\mathrm{K}_{\mathrm{b}} / \mathrm{K}_{\mathrm{c}}$} & $\mathrm{s}^{\prime} \quad($ Eqtn 2$)$ & $\lambda=\mathrm{P}_{\mathrm{cr}} / \mathrm{P}_{\mathrm{E}}$ \\
\hline 0 & 3.0 & 0 \\
$\left(\mathrm{~K}_{\mathrm{c}}>>\mathrm{K}_{\mathrm{b}}\right)$ & & \\
1.0 & 2.62 & 0.184 \\
$\left(\mathrm{~K}_{\mathrm{c}}=\mathrm{K}_{\mathrm{b}}\right)$ & & \\
10 & 2.47 & 0.249 \\
$\left(\mathrm{~K}_{\mathrm{c}}=0.1 \mathrm{~K}_{\mathrm{b}}\right)$ & & 0.25 \\
$\infty$ & 2.47 & \\
$\left(\mathrm{~K}_{\mathrm{c}}<<\mathrm{K}_{\mathrm{b}}\right)$ & & \\
\hline
\end{tabular}

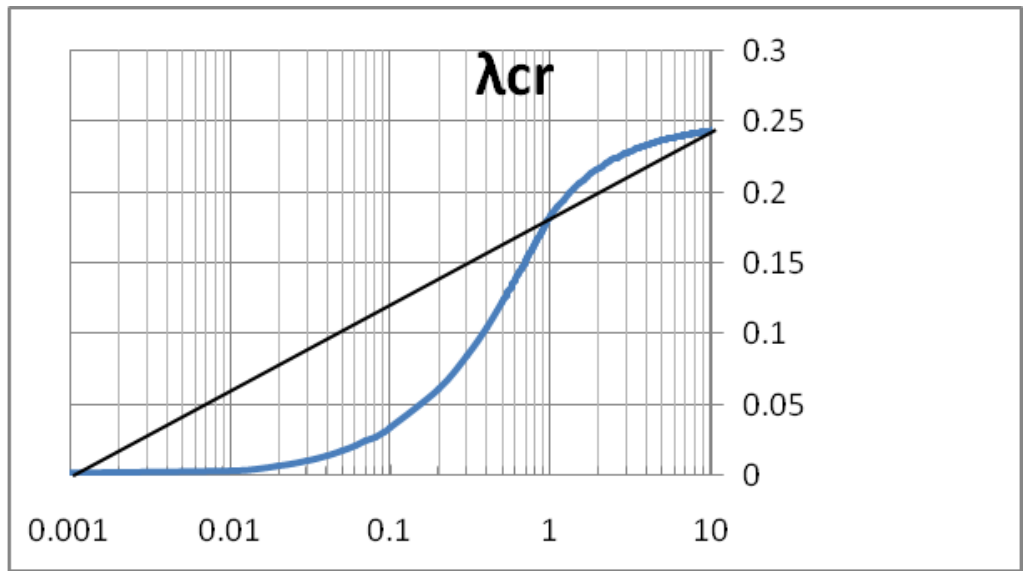

Fig. 4 Plot of $\mathrm{P}_{\mathrm{cr}} / \mathrm{P}_{\mathrm{E}}$ against $\log \mathrm{K}_{\mathrm{b}} / \mathrm{K}_{\mathrm{c}}$ for frame with pinned base support the two segments are clearly visible

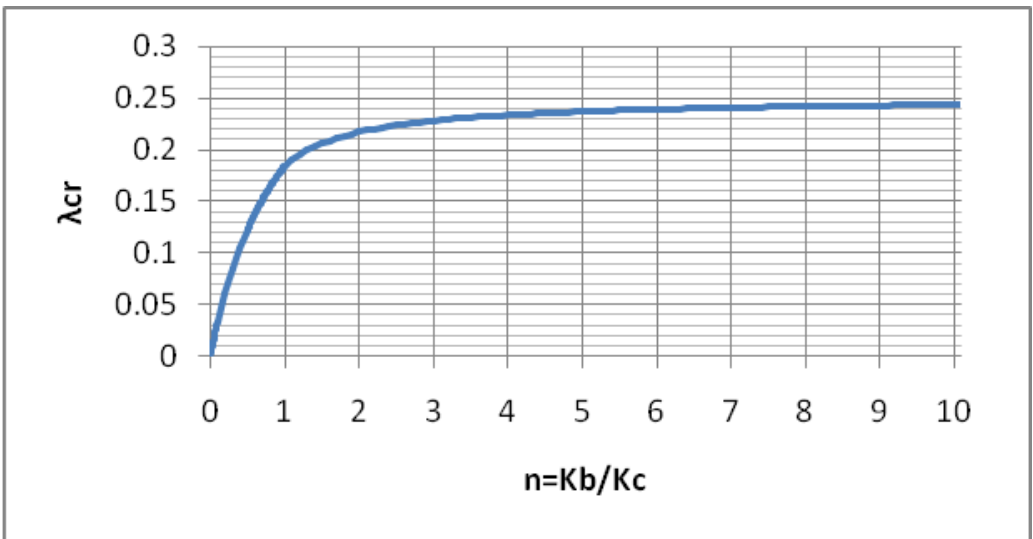

Fig. 5 Plot of $\mathrm{P}_{\mathrm{cr}} / \mathrm{P}_{\mathrm{E}}$ against $\mathrm{K}_{\mathrm{b}} / \mathrm{K}_{\mathrm{c}}$ for frame with pinned base support. Here the two segments are not visible

The Pcr curve has two distinct segments for $0.184 \leq \lambda \leq 0.25$ and $0 \leq \lambda \leq 0.184$

Using simple numerical integration, the following expressions are derived for the segments $0 \leq \mathrm{K}_{\mathrm{b}} / \mathrm{K}_{\mathrm{c}} \leq 1$ and $1 \leq \mathrm{K}_{\mathrm{b}} / \mathrm{K}_{\mathrm{c}}<\infty$ by Orumu ${ }^{7}$

For $\mathrm{K}_{\mathrm{b}} / \mathrm{K}_{\mathrm{c}}>1$

Pcr $=0.25 \mathrm{P}_{\mathrm{E}}\left(1-0.264 \mathrm{~K}_{\mathrm{c}} / \mathrm{K}_{\mathrm{b}}\right)$

For $\mathrm{K}_{\mathrm{b}} / \mathrm{K}_{\mathrm{c}}<1$

$\operatorname{Pcr}=\frac{18.4 \mathrm{PE}}{7.5(\mathrm{KC} / \mathrm{KB}))^{2}+916 \mathrm{KC} / \mathrm{KB}+685}$

\subsection{Determination of effective length}

Having determined the critical loads, the effective length of the entire frame can be obtained from known expression

$\mathrm{L}_{\mathrm{eff}}=\mathrm{L} \sqrt{\frac{\mathrm{PE}}{\mathrm{PCr}}}$ 
IV.

APPLICATION

Determine the critical load for a symmetrical sway frame for various values of beam to column stiffness ratios for feet conditions of fixed and pinned supports. Tabulate the results and compare with those obtained by Horne and Merchant ${ }^{3}$, on the basis of rigorous analysis by stability functions.

Table 3: Values of elastic critical load factor $(\lambda \mathrm{cr})$ for Sway Frame with fixed feet.

\begin{tabular}{|c|c|c|c|c|}
\hline $\mathrm{n}$ & $\lambda$ cr Orumu & $\lambda$ cr proposed & $\lambda$ cr Horne & effective length \\
\hline 0 & 0.25 & 0.2500 & 0.25 & 2.0 \\
\hline 0.1 & 0.35937394 & 0.342727 & 0.36 & 1.708149 \\
\hline 0.25 & 0.48317233 & 0.42 & & 1.543033 \\
\hline 0.5 & 0.61785371 & 0.59 & 0.61 & 1.301889 \\
\hline 0.75 & 0.70075037 & 0.687143 & & 1.206359 \\
\hline 0.8 & 0.7134561 & 0.703333 & 0.7 & 1.192393 \\
\hline 0.85 & 0.72518652 & 0.718649 & & 1.179619 \\
\hline 0.9 & 0.73604304 & 0.733158 & & 1.167888 \\
\hline 0.95 & 0.74611437 & 0.746923 & & 1.157076 \\
\hline 1 & 0.7554783 & 0.76 & 0.75 & 1.147079 \\
\hline 1.5 & 0.82198614 & 0.84 & & 1.091089 \\
\hline 2 & 0.86037702 & 0.88 & & 1.066004 \\
\hline 4 & 0.92514016 & 0.94 & 0.94 & 1.031421 \\
\hline 5 & 0.93921199 & 0.952 & & 1.0249 \\
\hline 8 & 0.96110011 & 0.97 & 0.97 & 1.015346 \\
\hline 9 & 0.96526347 & 0.973333 & & 1.013606 \\
\hline 10 & 0.96862046 & 0.976 & 0.98 & 1.01222 \\
\hline$\infty$ & 1 & 1.0 & 1 & 1.0 \\
\hline
\end{tabular}

Table 4: Values of elastic critical load factor ( $\lambda$ cr) for Sway Frame with pinned feet

\begin{tabular}{|r|c|r|r|r|}
\hline \multicolumn{1}{|c|}{$\mathrm{n}$} & $\lambda$ cr modified & $\lambda$ crproposed & $\lambda$ cr Horne & effective length \\
\hline 0 & 0 & 0 & 0 & $\infty$ \\
0.1 & 0.043402 & 0.040044 & 0.04 & 4.997282 \\
0.2 & 0.076082 & 0.075025 & 0.075 & 3.650864 \\
0.75 & 0.165833 & 0.164335 & & 2.466809 \\
0.8 & 0.169452 & 0.168542 & 0.167 & 2.435827 \\
0.85 & 0.172780 & 0.172423 & & 2.408257 \\
0.9 & 0.178695 & 0.176014 & & 2.383561 \\
1 & 0.198548 & 0.184 & 0.184 & 2.331262 \\
1.5 & 0.209796 & 0.206 & & 2.203263 \\
2 & 0.228556 & 0.217 & & 2.146694 \\
4 & 0.232608 & 0.2335 & 0.233 & 2.069458 \\
5 & 0.238897 & 0.2368 & & 2.054987 \\
8 & 0.240090 & 0.24175 & 0.242 & 2.03384 \\
9 & 0.241052 & 0.242667 & & 2.029995 \\
10 & 0.249907 & 0.2434 & & 2.026934 \\
\cline { 2 - 3 }$\infty$ & 0.25 & 0.25 & 0.25 & 2 \\
\cline { 2 - 3 } & \multicolumn{2}{|r|}{${ }^{2}$} & &
\end{tabular}

\section{DISCUSSION}

The results from the worked examples in tables 2 and 4 demonstrate the simplicity and accuracy of the proposed interpolative model for simple sway frames. The solutions from Horne and Merchant ${ }^{2}$ using the rigorous matrix computer analysis using stability functions are tabulated together with those from Orumu $\mathrm{u}^{9}$ and are used as accurate baseline values for comparison with the critical load. The results are shown to be very reliable when compared. A rather controversial problem by wood ${ }^{5}$ is discussed below for a particular case where the beam is 10I, a stocky column is 10I and a slender column of the sway frame is analyzed by the model as follows

For the slender column

$\mathrm{KB} / \mathrm{KC}=\mathrm{n}=1 \mathrm{O}$

and from table 3

$\lambda \mathrm{cr}=0.976$

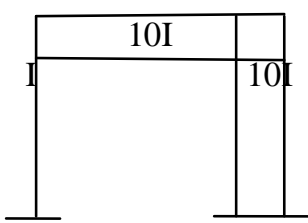


For the stocky column

$\mathrm{KB} / \mathrm{KC}=\mathrm{n}=1$

and from table 3

$\lambda \mathrm{cr}=0.76$

Remembering that the critical load factors as obtained above are functions of the Euler loads of the columns respectively, we need to bring them to the equivalent of the smaller column and otain the frame critical load factor, which has been shown in Orumu ${ }^{9}$ as a simple average of the two columns critical load. Thus

$\lambda \mathrm{cr}=(0.976+0.76 \times 10) 0.5$

$\lambda \mathrm{cr}=4.288$

The $\lambda \mathrm{cr}=4.288$ compares to that of $\mathrm{Wood}^{10}$ who had obtained a value of $\lambda \mathrm{cr}=4.3$. Orumu ${ }^{9}$ had values of $\lambda \mathrm{cr}=1.065$ and $\lambda \mathrm{cr}=3.98$ and reasoned that they appear to be the first and second mode buckling loads of the special frame. The frame will have failed before hitting Pcr $=3.98 \mathrm{PE}$ speaking from Engineering point of view. Orumu $^{9}$ therefore claimed that the critical load is Pcr $=1.065 \mathrm{PE}$. With comparison to the Wood ${ }^{5}$ the result obtained is exact. It is noteworthy to state here that the value of the critical load factor for a $\mathrm{KB} / \mathrm{KC}$ ratio of 1 was taken as 0.76 instead of 0.75 obtained from the use of stability functions to arrive at the interpolation equations. This has been obtained mathematically and used very much in literature.

\section{CONCLUSION}

The proposed interpolative model offer a most simplified hand solution to sway stability problems of building frames. Its success is justified by close reproduction of existing solutions of rigorous methods which is the basis upon which the numerical integration is performed to obtain the four equations of the model. Its application will impact on reducing cost of computing and increasing scope of solvable problems on sway stability of frames, while opening a greater scope for studies in this rather complex area of structural analysis and design. However, the basic theory may be lost by new comers who may not have had basic knowledge of the subject matter and just jump solving critical load problems with the equations derived in the interpolative technique.

\section{REFERENCES}

[1] Steven, LIK, "Elastic Stability of Practical Multi-storey Frames" Proceedings of the Institution of Civil Engineers; Vol. 36 Jan. 1967.

[2] Horne, M.R. and Merchant, W. “The Stability of Frames, Pergamon Press, New York, N.Y. 1965.

[3] Horne, M.R. "An Approximate Method for Calculating the Elastic Critical Loads of Multistorey Plane Frames". The Structural Engineer Vol. 53 No. 6 June, 1975.

[4] Bolton, A. "A Simple Understanding of Elastic Critical Loads". The Structural Engineer Vol. 54 No. June, 1976.

[5] Wood, R.H. "Effective Lengths of Columns in Multistory Buildings". The Structural Engineer Vol. 52 No. 8 August, 1984.

[6] Anderson D. "Simple Calculation of Elastic Critical Loads for Unbraced Multi-Storey Steel Frames". The Structural Engineer/Volume 58 No. 8 August 1980.

[7] Orumu, S.T. "The Stability of Sway Frames by Method of Superposition of Frames" Master's Degree Thesis submitted to the Rivers State University of Science and Technology, Port Harcourt, Nov. 1997.

[8] Hoenderkamp, J.C.D. "Critical Loads on Lateral Resisting Structures for Tall Buildings"'. Structural Design of Tall Buildings 1, 221-232, 2002. John Wiley and Sons: New York.

[9] Orumu, S.T. "Approximate Elastic Model for Determination of Critical Loads and Effective Lengths for Simple Sway Frames' The International Journal Of Engineering And Science (IJES) ||Volume ||2 ||Issue\| 8 ||Pages|| 113-120||2013|| ISSN(e): 2319 - $1813 \operatorname{ISSN}(p): 2319-1805$

[10] Livesley R.K. and Chandler, D.B. Stability Functions for Structural Frameworks. Manchester University Press 1956.

[11] F. David Edmonds and Ian C. Medland, “Approximate Determination of Frame Critical Loads". Journal of the Structural Division, Proceedings of ASCE. Vol. 98 No. ST3, March 1972.

[12] Zalka K.A. "Full-height Buckling of Frameworks with Cross-bracing". Proceedings of the Institute of Civil Engineers 134, May 1999, pp. 181-191. 